
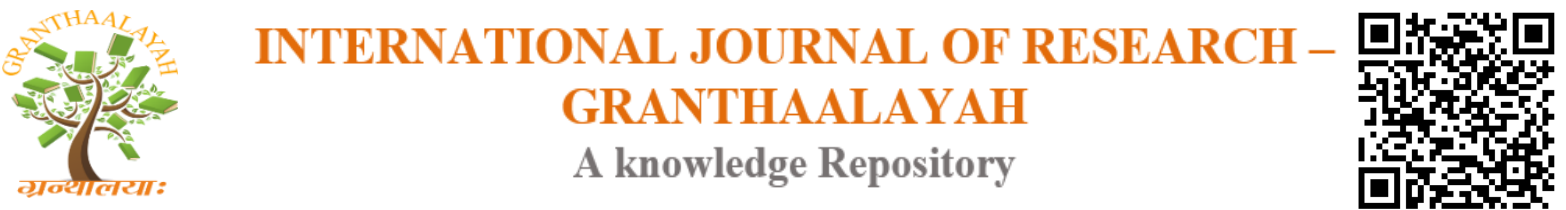

Science

\title{
ENHANCED MINE BLAST ALGORITHM FOR SOLVING REACTIVE POWER PROBLEM
}

\author{
Dr.K.Lenin *1 \\ ${ }^{* 1}$ Professor, Department of EEE, Prasad V.Potluri Siddhartha Institute of Technology, Kanuru, \\ Vijayawada, Andhra Pradesh -520007, India
}

\begin{abstract}
In this paper Enhanced Mine Blast (EMB) algorithm which based on mine bomb explosion concept is proposed to solve optimal reactive power problem. The clue of the projected Enhanced Mine Blast (EMB) algorithm is based on the examination of a mine bomb explosion, in which the thrown pieces of shrapnel crash with other mine bombs near the explosion area resulting in their explosion. In this paper convergence speed has been enhanced. Proposed Enhanced Mine Blast (EMB) algorithm has been tested in standard IEEE 118 \& practical 191 bus test systems and simulation results show clearly the superior performance of the projected Enhanced Mine Blast (EMB) algorithm in reducing the real power loss.
\end{abstract}

Keywords: Enhanced Mine Blast Algorithm; Optimal Reactive Power; Transmission Loss.

Cite This Article: Dr.K.Lenin. (2017). "ENHANCED MINE BLAST ALGORITHM FOR SOLVING REACTIVE POWER PROBLEM." International Journal of Research Granthaalayah, 5(9), 206-216. https://doi.org/10.29121/granthaalayah.v5.i9.2017.2232.

\section{Introduction}

Various algorithms are employed to solve the Reactive Power problem. Dissimilar types of arithmetical methods like the gradient method [1-2], Newton method [3] and linear programming [4-7] have been previously used to solve the optimal reactive power problem. The voltage stability problem plays a central role in power system planning and operation [8].Evolutionary algorithms such as genetic algorithm, Hybrid differential evolution algorithm, Biogeography Based algorithm, a fuzzy based approach, an improved evolutionary programming [9-15] have been already utilized to solve the reactive power flow problem In [16-18] different methodologies are effectively handled the optimal power problem. In [19-20], a programming based approach and probabilistic algorithm is used to solve the optimal reactive power problem. This paper introduces a new Enhanced Mine Blast (EMB) algorithm is used to solve optimal reactive power problem. In Mine Blast Algorithm the concepts are enthused form the explosion of mine bombs in actual life situations. In this paper the convergence speed has been improved. Proposed Enhanced Mine Blast (EMB) algorithm has been evaluated in standard IEEE 118 \& practical 191 bus test systems. The simulation results show that the proposed Enhanced Mine 
Blast (EMB) algorithm outperforms all the entitled reported algorithms in minimization of real power loss.

\section{Problem Formulation}

The OPF problem is considered as a general minimization problem with constraints, and can be written in the following form:

Minimize $\mathrm{f}(\mathrm{x}, \mathrm{u})$

Subject to $g(x, u)=0$

and

$\mathrm{h}(\mathrm{x}, \mathrm{u}) \leq 0$

Where $f(x, u)$ is the objective function. $g(x . u)$ and $h(x, u)$ are respectively the set of equality and inequality constraints. $\mathrm{x}$ is the vector of state variables, and $\mathrm{u}$ is the vector of control variables.

The state variables are the load buses (PQ buses) voltages, angles, the generator reactive powers and the slack active generator power:

$\mathrm{x}=\left(\mathrm{P}_{\mathrm{g} 1}, \theta_{2}, \ldots, \theta_{\mathrm{N}}, \mathrm{V}_{\mathrm{L} 1}, \ldots, \mathrm{V}_{\mathrm{LNL}}, \mathrm{Q}_{\mathrm{g} 1}, \ldots, \mathrm{Q}_{\mathrm{gng}}\right)^{\mathrm{T}}$

The control variables are the generator bus voltages, the shunt capacitors/reactors and the transformers tap-settings:

$\mathrm{u}=\left(\mathrm{V}_{\mathrm{g}}, \mathrm{T}, \mathrm{Q}_{\mathrm{c}}\right)^{\mathrm{T}}$

or

$\mathrm{u}=\left(\mathrm{V}_{\mathrm{g} 1}, \ldots, \mathrm{V}_{\mathrm{gng}}, \mathrm{T}_{1}, \ldots, \mathrm{T}_{\mathrm{Nt}}, \mathrm{Q}_{\mathrm{c} 1}, \ldots, \mathrm{Q}_{\mathrm{cNc}}\right)^{\mathrm{T}}$

Where $\mathrm{Ng}, \mathrm{Nt}$ and $\mathrm{Nc}$ are the number of generators, number of tap transformers and the number of shunt compensators respectively.

\section{Objective Function}

\section{Active Power Loss}

The objective of the reactive power dispatch is to minimize the active power loss in the transmission network, which can be described as follows:

$F=P L=\sum_{k \in N b r} g_{k}\left(V_{i}^{2}+V_{j}^{2}-2 V_{i} V_{j} \cos \theta_{i j}\right)$

or

$F=P L=\sum_{i \in N g} P_{g i}-P_{d}=P_{g s l a c k}+\sum_{i \neq s l a c k}^{N g} P_{g i}-P_{d}$

Where $g_{k}$ : is the conductance of branch between nodes $i$ and $j$, Nbr: is the total number of transmission lines in power systems. $\mathrm{P}_{\mathrm{d}}$ : is the total active power demand, $\mathrm{P}_{\mathrm{gi}}$ : is the generator active power of unit $i$, and $P_{\text {gsalck: }}$ is the generator active power of slack bus. 


\section{Voltage Profile Improvement}

For minimizing the voltage deviation in PQ buses, the objective function becomes:

$F=P L+\omega_{v} \times V D$

Where $\omega_{\mathrm{v}}$ : is a weighting factor of voltage deviation.

VD is the voltage deviation given by:

$V D=\sum_{i=1}^{N p q}\left|V_{i}-1\right|$

\section{Equality Constraint}

The equality constraint $\mathrm{g}(\mathrm{x}, \mathrm{u})$ of the ORPD problem is represented by the power balance equation, where the total power generation must cover the total power demand and the power losses:

$P_{G}=P_{D}+P_{L}$

This equation is solved by running Newton Raphson load flow method, by calculating the active power of slack bus to determine active power loss.

\section{Inequality Constraints}

The inequality constraints $\mathrm{h}(\mathrm{x}, \mathrm{u})$ reflect the limits on components in the power system as well as the limits created to ensure system security. Upper and lower bounds on the active power of slack bus, and reactive power of generators:

$P_{\text {gslack }}^{\min } \leq P_{\text {gslack }} \leq P_{\text {gslack }}^{\max }$

$Q_{g i}^{\min } \leq Q_{g i} \leq Q_{g i}^{\max }, i \in N_{g}$

Upper and lower bounds on the bus voltage magnitudes:

$V_{i}^{\min } \leq V_{i} \leq V_{i}^{\max }, i \in N$

Upper and lower bounds on the transformers tap ratios:

$T_{i}^{\text {min }} \leq T_{i} \leq T_{i}^{\max }, i \in N_{T}$

Upper and lower bounds on the compensators reactive powers:

$Q_{C}^{\min } \leq Q_{c} \leq Q_{C}^{\max }, i \in N_{C}$

Where $\mathrm{N}$ is the total number of buses, $\mathrm{N}_{\mathrm{T}}$ is the total number of Transformers; $\mathrm{N}_{\mathrm{c}}$ is the total number of shunt reactive compensators. 


\section{Mine Blast Algorithm}

The idea of the projected algorithm is based on the observation of a mine bomb explosion, in which the thrown pieces of shrapnel crash with other mine bombs near the explosion area resulting in their explosion $[21,22]$. To understand this situation, consider a mine field where the aim is to clear the mines. Hence, the aim is to find the mines, while importantly to find the one with the most explosive effect located at the optimal point $\mathrm{X}^{*}$ which can cause the most casualties ( $\min$ or $\max \mathrm{f}(\mathrm{x})$ per $\mathrm{X}^{*}$ ). The mine bombs of different sizes and explosive powers are planted under the ground. When a mine bomb is exploded, it spreads many shrapnel pieces and the casualties $(f(x))$ caused byeach piece of shrapnel are calculated. A high value for casualtiesper piece of shrapnel in an area may designate the existence of other mines which may or may not have higher explosive power. Each shrapnel piece has certain directions and distances to collide with other mine bombs which may lead to the explosion of other mines due to the collision. The collision of shrapnel pieces with other mines may lead us to discover the most explosive mine. The casualties caused by the explosion of a mine bomb are considered as the fitness of the objective function at the mine bomb's location. The domain (mine field) solution may be divided into infinite grid where there is one mine bomb in each portion of the grid. The Mine Blast Algorithm starts with an initial point(s) called the first shot point(s). The first shot point is represented by $X_{0}^{f}$. The superscript $\mathrm{f}$ refers to the number of first shot point(s) (f $=1,2$, $3, \ldots$ ), where $\mathrm{f}$ can be a user defined parameter. However, the algorithm can also arbitrarily choose the location(s) of the first shot point(s) using the lower and upper bound values of a problem. This algorithm requires apreliminary population of individuals as is the case with several other metaheuristic methods. This population is generated by a first shot explosion producing a number of individuals (shrapnel pieces). The number of initial population $\left(\mathrm{N}_{\text {pop }}\right)$ is considered as the number of shrapnel pieces $\left(\mathrm{N}_{\mathrm{s}}\right)$. The algorithm uses the lower and upper bound values specified by a problem. It then creates the first shot point value by a small randomly generated value given as:

$X_{0}=L B+\operatorname{rand} \times(U B-L B)$

where $\mathrm{X}_{0}, \mathrm{LB}$ and UB are the produced first shot point, lower and upper bounds of the problem, respectively. randis a uniformly distributed arbitrary number between 0 and 1. Although in all optimization simulations conducted in this research one first shot point was used efficiently, however, more than one first shot points may be used which results in an increase in the preliminary population and subsequently results in an increase in the number of function evaluations (computational cost). Suppose that $\mathrm{X}$ is the current location of a mine bomb given as:

$X=\left\{X_{m}\right\}, m=1,2,3, \ldots, N_{d}$

in which $\mathrm{N}_{\mathrm{d}}$ is the search space dimension equal to the number of independent variables. Ponder that $\mathrm{N}_{\mathrm{s}}$ shrapnel pieces are produced by the mine bomb explosion causing another mine to explode at $\mathrm{Xn}+1$ location:

$X_{n+1}^{f}=X_{e(n+1)}^{f}+\exp \left(-\sqrt{\frac{m_{n+1}^{f}}{d_{n+1}^{f}}}\right) X_{n}^{f}, n=0,1,2,3$. 
Where $X_{e(n+1)}^{f}, d_{n+1}^{f}, m_{n+1}^{f}$ are the location of exploding mine bomb collided by shrapnel, the distance and the direction (slope) of the thrown shrapnel pieces in each iteration, respectively. The location of exploding mine bomb $X_{e(n+1)}^{f}$ is defined as:

$X_{e(n+1)}^{f}=d_{n}^{f} \times \operatorname{rand} \times \cos (\theta), n=0,1,2$.

Where rand is a uniformly distributed random number and $\theta$ is the angle of the shrapnel pieces which is a constant value and is calculated using $\theta=360 /$ Ns.

The concept of Eq. (20) is to simulate the explosion of mine bombs in the real world. Each shrapnel pieces (individual), having variable distances from the point of explosion and definite directions, explore the domain space in $360^{\circ}$ at each iteration specified by $\theta$ and $d_{n}^{f}$ in order to find the best optimal point. The value of $\theta$ is set to $360 / \mathrm{N}_{\mathrm{s}}$ in order to conduct uniform search in the domain space. This can prevent the accumulation of individuals in a specific region of the domain search.

The exponential term in Eq. (19) is used to improve the obtained blast point by influencing the information from previous solutions $\left(X_{n}^{f}\right)$. The distance $d_{n+1}^{f}$ and the direction of shrapnel pieces $m_{n+1}^{f}$ are defined as:

$$
\begin{aligned}
& d_{n+1}^{f}=\sqrt{\left(X_{n+1}^{f}-X_{n}^{f}\right)^{2}+\left(F_{n+1}^{f}-F_{n}^{f}\right)^{2}} n=0,1,2, . . \\
& m_{n+1}^{f}=\frac{F_{n+1}^{f}-F_{n}^{f}}{X_{n+1}^{f}-X_{n}^{f}} n=0,1,2, \ldots
\end{aligned}
$$

Where $\mathrm{F}$ is the function value for the $\mathrm{X}$. To calculate the initial distance for each shrapnel pieces $\mathrm{d}_{0}=(\mathrm{UB}-\mathrm{LB})$ in each dimensions is used. The initial distance given by the algorithm issued to search the best solution within a range (LB $\left.<\mathrm{d}_{0}<\mathrm{UB}\right)$ that is computed by the product of the initial distance and a randomly created number. Additionally, in order to conduct exploration of the design space at smaller and larger distances, the exploration factor $(\mu)$ is introduced. This constant, which is used in the primary iterations of the algorithm, is compared with an iteration number index $(\mathrm{k})$, and if it is higher than $\mathrm{k}$, then the exploration process begins. The equations for the exploration of the solution space are given as:

$d_{n+1}^{f}=d_{n}^{f} \times(|\operatorname{randn}|)^{2} n=0,1,2$

$X_{e(n+1)}^{f}=d_{n}^{f} \times \cos (\theta), n=0,1,2$.

Where rand $\mathrm{n}$ is normally distributed pseudorandom number. During the exploration process when the $\mu$ is applied, the distance of each shrapnel piecesis modified using Eq. (23). The square of a normally distributed randomnumber offers the advantage of search ability at smaller and 
larger distances giving better exploration in early iterations. Therefore, the exploration process shifts the shrapnel pieces closer to the optimum point in early iterations. A higher value for the exploration factor $(\mu)$ makes it possible to explore more remote regions (better exploration), thus, the value of $\mu$ determines the intensity of theexploration.To increase the global search ability of the method, initial distance of shrapnel pieces are reduced gradually to allow the mine bombs search the probable global minimum location. The reduction in $d_{0}^{f}$ is given as:

$d_{n}^{f}=\frac{d_{n-1}^{f}}{\exp (k / \alpha)} \quad n=1,2,3$

Where $\alpha$ and $\mathrm{k}$ are reduction constants and iteration number index, respectively. The choice of $\alpha$ which is user parameter depends onthe complexity of the problem. The effect of $\alpha$ is to reduce thedistance of each shrapnel pieces adaptively using Eq. (25). Thus the whole interval from lower bound to upper bound for a given problem is searched. At the final iteration, the value of distance of shrapnel will be approximately equal to zero .The schematic diagram of the algorithm representing two aspects of the Mine blast Algorithm (MBA) (exploration in colour lines and exploitation in black colour lines) is shown in Fig. 1 [22].

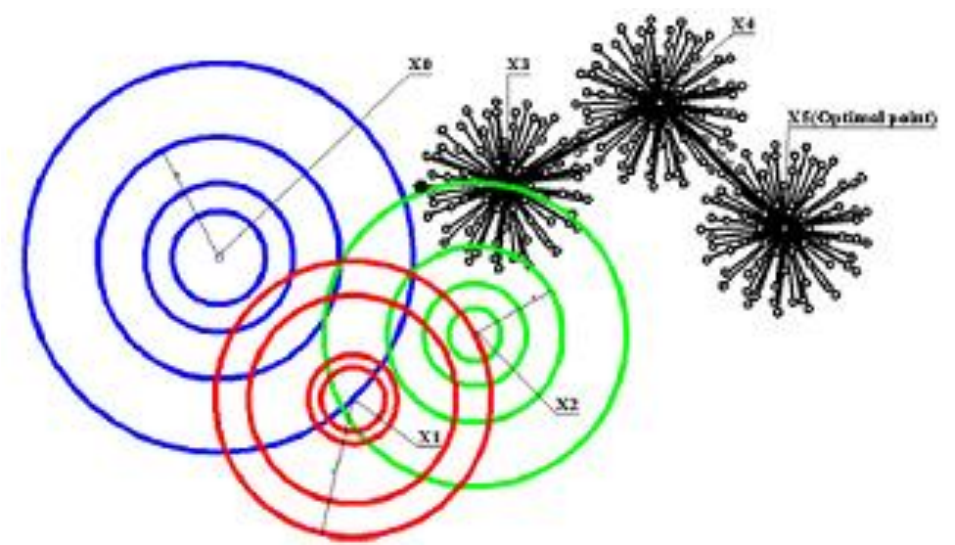

Figure 1: Schematic view of the mine blast algorithm including of exploration (colour lines) and exploitation (black lines) processes.

Based on Fig. 1, there are two processes for searching the solution domain in order to find the global optimum solution, the exploration and exploitation processes. The difference between these two processes is how they influence the whole search process toward the optimal solution. More specifically, the exploration factor describes the exploration process (colour lines in Fig. 1). The exploration factor $(\mu)$ represents the number of first iterations.Hence, if $\mu$ is set to 10 , then for 10 iterations the algorithm usesEqs. (23) and (24) for calculating the distance of shrapnel pieces and the location of the exploded mine bomb, respectively. On the other hand, for the exploitation process (black lines in Fig. 1), the algorithm is encouraged to focus on the optimal point. In particular, with respect to the exploitation process, the proposed algorithm converges to the global optimum solution using Equations.(20) - (22) to calculate the location of exploded mine bomb, distance and the direction of shrapnel pieces, respectively. The distance of shrapnel pieces is reduced adaptively using Eq. (25) in exploitation process (i.e., as it converges to the optimal solution). The pseudo code for the exploration and exploitation processes is as follows: 
If $\mu>\mathrm{k}$

Exploration (Eqs.(23) and (24))

Else

Exploitation (Eqs.(20)-(22), and (25))

End

Where $\mathrm{k}$ is the iteration number index.

In the present work, a modified feasible-based mechanism is used to handle the problem specific constraints which consist of the following four rules [23]:

- Rule 1: Any feasible solution is preferred to any infeasible solution.

- Rule 2: Infeasible solutions containing slight violation of the constraints (from 0.01 in the first iteration to 0.001 in the last iteration) are considered as feasible solutions.

- Rule 3: Between two feasible solutions, the one having the better objective function value is preferred.

- Rule 4: Between two infeasible solutions, the one having the smaller sum of constraint violation is preferred.

By using the first and fourth rules, the search is oriented to the feasible region rather than to the infeasible region, and by employing the third rule the search is directed to the feasible region with good solutions [23]. For most structural optimization problems, the global minimum locates on or close to the boundary of a feasible design space. By applying rule 2, the shrapnel pieces approach the boundaries and can reach the global minimum with a higher probability [24].Fig. 2 [22] shows the constraint handling approach by the Mine blast algorithm (MBA). As can be seen from Fig. 2, in the search space, shrapnel pieces may violate either the problem specific constraints or the limits of the design variables. In this case, the distance of infeasible shrapnel piece (e.g. $\mathrm{X}_{3}$ in Fig. 2) is reduced adaptively using Eq. (25) whereas that violated shrapnel piece is also placed in the feasible region.

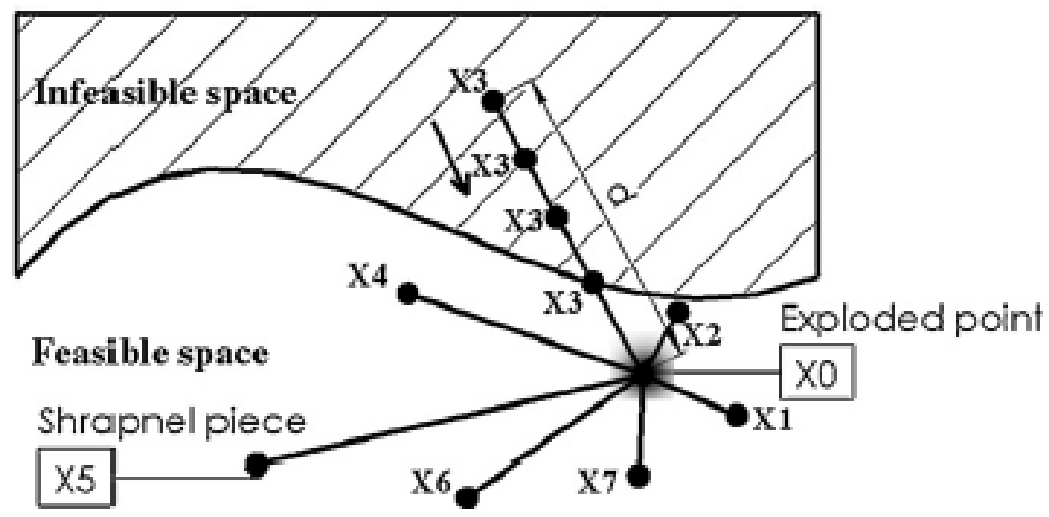

Figure 2: Schematic view of constraint handling approach using the MBA method.

For termination criteria, as usually considered in metaheuristic algorithms, the best result is calculated where the termination condition may be assumed as the maximum number of iterations, CPU time, or $\varepsilon$ which is a small value and is definedas an allowable tolerance between the last two results. The MBAcontinues until the above convergence criteria are satisfied. 


\section{Enhanced Mine Blast (EMB) Algorithm}

The alteration achieved by having distance between current exploded point $X_{e(n+1)}$ and current best solution so far $X_{\text {best }}$. The proposed amendment is given below,

$X_{n+1}^{f}=X_{e(n+1)}+\exp \left(-\sqrt{\frac{1}{D}}\right) \times \operatorname{rand} \otimes\left\{X_{\text {best }}-X_{e(n+1)}\right\}, n=1,2,3$.

$D=\left[\sum_{i=1}^{m}\left(X_{\text {ibest }}-X_{e(n+1)}\right)^{2}\right]^{1 / 2}$

Where D represents Euclidean distances between current best solution $X_{\text {ibest }}$ and current point of explosion $X_{e(n+1)}$ in $\mathrm{m}$ dimensions. The projected approach did not use information of previous best location, therefore it improve the speed the convergence of the algorithm.

\section{Enhanced Mine Blast (EMB) algorithm for solving optimal reactive power problem,}

a) Choose the preliminary parameters: Ns, $\mu, \alpha$, and maximum number of iterations.

b) Verify the condition of exploration factor $(\mu)$.

c) If condition of exploration factor is satisfied, calculate the distance of shrapnel pieces and their locations according to Eqs. (23) and (24), respectively. Else, go to Step 10.

d) Calculate the direction of shrapnel pieces according to Eq. (22).

e) Create the shrapnel pieces and calculate their improved locations using Eq. $(19,26,27)$.

f) Check the constraints for generated shrapnel pieces.

g) Accumulate the best shrapnel piece as the best temporal solution.

h) Does the shrapnel piece have the lower function value than the best temporal solution?

i) If true, swap the position of the shrapnel piece with the finest temporal solution. Else, go to Step j.

j) Calculate the distance of shrapnel pieces and their locations using Eqs. (20) and (21) and return to Step 4.

k) Reduce the distance of the shrapnel pieces adaptively using Eq. (25).

1) Check the convergence criteria. If the stopping criterion is satisfied, the algorithm will be stopped. Else, return to Step b.

\section{Simulation Results}

At first Enhanced Mine Blast (EMB) algorithm has been tested in standard IEEE 118-bus test system [25].The system has 54 generator buses, 64 load buses, 186 branches and 9 of them are with the tap setting transformers. The limits of voltage on generator buses are $0.95-1.1$ per-unit., and on load buses are $0.95-1.05$ per-unit. The limit of transformer rate is $0.9-1.1$, with the changes step of 0.025 . The limitations of reactive power source are listed in Table 1, with the change in step of 0.01 .

Table 1: Limitation of reactive power sources

\begin{tabular}{|l|l|l|l|l|l|l|l|}
\hline BUS & 5 & 34 & 37 & 44 & 45 & 46 & 48 \\
\hline QCMAX & 0 & 14 & 0 & 10 & 10 & 10 & 15 \\
\hline QCMIN & -40 & 0 & -25 & 0 & 0 & 0 & 0 \\
\hline BUS & 74 & 79 & 82 & 83 & 105 & 107 & 110 \\
\hline
\end{tabular}




\begin{tabular}{|l|l|l|l|l|l|l|l|}
\hline QCMAX & 12 & 20 & 20 & 10 & 20 & 6 & 6 \\
\hline QCMIN & 0 & 0 & 0 & 0 & 0 & 0 & 0 \\
\hline
\end{tabular}

The statistical comparison results of 50 trial runs have been list in Table 2 and the results clearly show the better performance of proposed Enhanced Mine Blast (EMB) algorithm.

Table 2: Comparison results

\begin{tabular}{|l|l|l|l|l|}
\hline Active power loss (p.u) & $\begin{array}{l}\text { BBO } \\
{[\mathbf{2 6}]}\end{array}$ & $\begin{array}{l}\text { ILSBBO/ } \\
\text { strategy1 [26] }\end{array}$ & $\begin{array}{l}\text { ILSBBO/ } \\
\text { strategy1 [26] }\end{array}$ & $\begin{array}{l}\text { Proposed } \\
\text { EMB }\end{array}$ \\
\hline Min & 128.77 & 126.98 & 124.78 & 115.38 \\
\hline Max & 132.64 & 137.34 & 132.39 & 119.92 \\
\hline Average & 130.21 & 130.37 & 129.22 & 116.46 \\
\hline
\end{tabular}

Then the Enhanced Mine Blast (EMB) algorithm has been tested in practical 191 test system and the following results have been obtained. In Practical 191 test bus system - Number of Generators $=20$, Number of lines $=200$, Number of buses $=191$ Number of transmission lines $=$ 55. Table 3 shows the optimal control values of practical 191 test system obtained by EMB method. And table 4 shows the results about the value of the real power loss by obtained by Enhanced Mine Blast (EMB) algorithm.

Table 3: Optimal Control values of Practical 191 utility (Indian) system by EMB method

\begin{tabular}{l|l|l|l|l}
\hline VG1 & 1.10 & VG 11 & 0.90 \\
\hline VG 2 & 0.70 & & VG 12 & 1.00 \\
\hline VG 3 & 1.01 & VG 13 & 1.00 \\
\hline VG 4 & 1.01 & VG 14 & 0.90 \\
\hline VG 5 & 1.10 & VG 15 & 1.00 \\
\hline VG 6 & 1.10 & VG 16 & 1.00 \\
\hline VG 7 & 1.10 & VG 17 & 0.90 \\
\hline VG 8 & 1.01 & VG 18 & 1.00 \\
\hline VG 9 & 1.10 & VG 19 & 1.10 \\
\hline VG 10 & 1.01 & VG 20 & 1.10 \\
\hline
\end{tabular}

\begin{tabular}{|c|c|c|c|c|c|}
\hline $\mathrm{T} 1$ & 1.00 & T21 & 0.90 & $\mathrm{~T} 41$ & 0.90 \\
\hline $\mathrm{T} 2$ & 1.00 & $\mathrm{~T} 22$ & 0.90 & $\mathrm{~T} 42$ & 0.90 \\
\hline T3 & 1.00 & $\mathrm{~T} 23$ & 0.90 & T43 & 0.91 \\
\hline $\mathrm{T} 4$ & 1.10 & $\mathrm{~T} 24$ & 0.90 & T44 & 0.91 \\
\hline T5 & 1.00 & $\mathrm{~T} 25$ & 0.90 & T45 & 0.91 \\
\hline T6 & 1.00 & T26 & 1.00 & T46 & 0.90 \\
\hline $\mathrm{T} 7$ & 1.00 & $\mathrm{~T} 27$ & 0.90 & T47 & 0.91 \\
\hline T8 & 1.01 & T28 & 0.90 & T48 & 1.00 \\
\hline T9 & 1.00 & $\mathrm{~T} 29$ & 1.01 & T49 & 0.90 \\
\hline $\mathrm{T} 10$ & 1.00 & $\mathrm{~T} 30$ & 0.90 & T50 & 0.90 \\
\hline $\mathrm{T} 11$ & 0.90 & $\mathrm{~T} 31$ & 0.90 & T51 & 0.90 \\
\hline T12 & 1.00 & T32 & 0.90 & T52 & 0.90 \\
\hline
\end{tabular}




\begin{tabular}{|c|c|c|c|c|c|}
\hline $\mathrm{T} 13$ & 1.01 & T33 & 1.01 & T53 & 1.00 \\
\hline T14 & 1.01 & T34 & 0.90 & T54 & 0.90 \\
\hline T15 & 1.01 & T35 & 0.90 & T55 & 0.90 \\
\hline T19 & 1.02 & T39 & 0.90 & & \\
\hline $\mathrm{T} 20$ & 1.01 & $\mathrm{~T} 40$ & 0.90 & & \\
\hline
\end{tabular}

Table 4: Optimum real power loss values obtained for practical 191 utility (Indian) system by EMB method.

\begin{tabular}{l|l}
\hline Real power Loss (MW) & EMB \\
\hline Min & 143.164 \\
\hline Max & 147.152 \\
\hline Average & 144.138 \\
\hline
\end{tabular}

\section{Conclusion}

Proposed Enhanced Mine Blast (EMB) algorithm has been successfully solved reactive power problem. Enhanced Mine Blast (EMB) algorithm is applied to obtain the optimal control variables so as to minimize the real power loss the system. The proposed algorithm has been tested in standard IEEE 118 \& practical 191 bus test systems. And the results were compared with other standard algorithms. Simulation study make known about the most excellent performance of the projected algorithm in reducing the real power loss and voltage profiles are well within the limits

\section{References}

[1] O.Alsac,and B. Scott, "Optimal load flow with steady state security",IEEE Transaction. PAS 1973, pp. 745-751.

[2] Lee K Y ,Paru Y M , Oritz J L -A united approach to optimal real and reactive power dispatch , IEEE Transactions on power Apparatus and systems 1985: PAS-104 : 1147-1153

[3] A.Monticelli , M .V.F Pereira ,and S. Granville , "Security constrained optimal power flow with post contingency corrective rescheduling", IEEE Transactions on Power Systems :PWRS-2, No. 1, pp.175-182.,1987.

[4] DeebN ,Shahidehpur S.M ,Linear reactive power optimization in a large power network using the decomposition approach. IEEE Transactions on power system 1990: 5(2) : 428-435

[5] E. Hobson ,'Network consrained reactive power control using linear programming, ' IEEE Transactions on power systems PAS -99 (4) ,pp 868=877, 1980

[6] K.Y Lee ,Y.M Park , and J.L Oritz, "Fuel -cost optimization for both real and reactive power dispatches", IEE Proc; 131C,(3), pp.85-93.

[7] M.K. Mangoli, and K.Y. Lee, "Optimal real and reactive power control using linear programming”, Electr.PowerSyst.Res, Vol.26, pp.1-10,1993.

[8] C.A. Canizares , A.C.Z.de Souza and V.H. Quintana, " Comparison of performance indices for detection of proximity to voltage collapse," vol. 11. no.3 , pp.1441-1450, Aug 1996.

[9] K.Anburaja, "Optimal power flow using refined genetic algorithm", Electr.PowerCompon.Syst , Vol. 30, 1055-1063,2002.

[10] D. Devaraj, and B. Yeganarayana, "Genetic algorithm based optimal power flow for security enhancement”, IEE proc-Generation.Transmission and. Distribution; 152, 6 November 2005. 
[11] A. Berizzi, C. Bovo, M. Merlo, and M. Delfanti, "A ga approach to compare orpf objective functions including secondary voltage regulation," Electric Power Systems Research, vol. 84, no. 1, pp. $187-194,2012$.

[12] C.-F. Yang, G. G. Lai, C.-H.Lee, C.-T. Su, and G. W. Chang, "Optimal setting of reactive compensation devices with an improved voltage stability index for voltage stability enhancement," International Journal of Electrical Power and Energy Systems, vol. 37, no. 1, pp. $50-57,2012$.

[13] P. Roy, S. Ghoshal, and S. Thakur, "Optimal var control for improvements in voltage profiles and for real power loss minimization using biogeography based optimization," International Journal of Electrical Power and Energy Systems, vol. 43, no. 1, pp. 830 - 838, 2012.

[14] B. Venkatesh, G. Sadasivam, and M. Khan, "A new optimal reactive power scheduling method for loss minimization and voltage stability margin maximization using successive multi-objective fuzzy lp technique," IEEE Transactions on Power Systems, vol. 15, no. 2, pp. 844 - 851, may 2000.

[15] W. Yan, S. Lu, and D. Yu, "A novel optimal reactive power dispatch method based on an improved hybrid evolutionary programming technique," IEEE Transactions on Power Systems, vol. 19, no. 2, pp. $913-918$, may 2004.

[16] W. Yan, F. Liu, C. Chung, and K. Wong, "A hybrid genetic algorithminterior point method for optimal reactive power flow," IEEE Transactions on Power Systems, vol. 21, no. 3, pp. 1163 1169, aug. 2006.

[17] J. Yu, W. Yan, W. Li, C. Chung, and K. Wong, "An unfixed piecewiseoptimal reactive powerflow model and its algorithm for ac-dc systems," IEEE Transactions on Power Systems, vol. 23, no. 1 , pp. $170-176$, feb. 2008.

[18] F. Capitanescu, "Assessing reactive power reserves with respect to operating constraints and voltage stability," IEEE Transactions on Power Systems, vol. 26, no. 4, pp. 2224-2234, nov. 2011.

[19] Z. Hu, X. Wang, and G. Taylor, "Stochastic optimal reactive power dispatch: Formulation and solution method," International Journal of Electrical Power and Energy Systems, vol. 32, no. 6, pp. $615-621,2010$.

[20] A. Kargarian, M. Raoofat, and M. Mohammadi, "Probabilistic reactive power procurement in hybrid electricity markets with uncertain loads," Electric Power Systems Research, vol. 82, no. 1, pp. $68-80,2012$.

[21] A. Sadollah, A. Bahreininejad, H. Eskandar, M. Hamdi, Mine blast algorithm foroptimization of truss structures with discrete variables, Computers \& Structures102-103 (2012) 49-63.

[22] Ali Sadollaha, ArdeshirBahreininejada, HadiEskandarb, MohdHamdia,Mine blast algorithm: A new population based algorithm for solving constrained engineering optimization problems,Applied Soft Computing 13 (2013) 2592-2612.

[23] E.M. Montes, C.A.C. Coello, An empirical study about the usefulness of evolution strategies to solve constrained optimization problems, International Journal ofGeneral Systems 37 (2008) 443-473.

[24] A. Kaveh, S. Talatahari, A particle swarm ant colony optimization for truss structures with discrete variables, Journal of Constructional Steel Research 65 (2009)1558-1568.

[25] IEEE, “The IEEE 30-bus test system and the IEEE 118-test system”, (1993), http://www.ee.washington.edu/trsearch/pstca/.

[26] Jiangtao Cao, Fuli Wang and Ping Li, "An Improved Biogeography-based Optimization Algorithm for Optimal Reactive Power Flow", International Journal of Control and Automation Vol.7, No.3 (2014), pp.161-176.

*Corresponding author.

E-mail address: gklenin@ gmail.com 